\title{
Maternidade para escravas no Rio de Janeiro (1850-1889)
}

\section{Maternity Ward for slaves in Rio de Janeiro (1850-1889)}

\author{
Maria Renilda Barreto*
}

\begin{abstract}
Resumo
O artigo tem por objetivo ampliar a discussão sobre a história da assistência à saúde da população cativa, em particular a criação de espaços específicos para partos. Trata-se da Maternidade Santa Isabel criada no último quartel do século XIX, inserida no cenário escravista e atravessada pelo discurso médico-científico, pelo ideal caritativo, eurocêntrico e reducionista. Essa reflexão soma-se a outras investigações que problematizam o organização de um aparato de cuidados à saúde dos escravos e escravas, agregando contribuições historiográficas às consagradas pesquisas sobre escravidão no Brasil. A documentação examinada encontra-se sob guarda do Arquivo Geral da Cidade do Rio de Janeiro e revela como a maternidade carioca tornou-se um projeto matizado por interesses científicos, pedagógicos e de assistência à saúde, na lógica da mentalidade escravista do Brasil Imperial.
\end{abstract}

Palavras Chaves: história da assistência - história da maternidade - escravidão

\begin{abstract}
The article aims to broaden the discussion about the history of health care for the captive population, in particular the creation of specific spaces for childbirths. It explores the Santa Isabel Maternity Ward that was created in the last quarter of the Nineteenth Century. It was situated in a setting of slavery and was intersected by medical-scientific discourse and by the Eurocentric and reductionist charitable ideal. This reflection adds to other studies that problematize the organization of a health care apparatus for slaves, bringing in historiographical contributions to the research dedicated to slavery in Brazil. The documentation examined is under the custody of the General Archive of Rio de Janeiro City and reveals how that maternity ward in Rio de Janeiro became a projected colored by scientific, pedagogical, and health care interests under the logic of the slave mentality of Imperial Brazil.
\end{abstract}

Keywords: history of care, maternity history, slavery

\footnotetext{
*Doutora em História das Ciências (FIOCRUZ), professora e pesquisadora do Centro Federal de Educação Tecnológica Ceslo Suckow da Fonseca (CEFET/RJ). A pesquisa apresentada foi financiada por FAPERJ, CNPq e CEFET/RJ. Agradeço as leituras e contribuições de Raquel Dalta, Maria Martha Freire e Renato Franco. E-mail: renildabarreto@hotmail.com
} 
Ao longo dos últimos anos observa-se o crescimento dos trabalhos historiográficos acerca da assistência à saúde da população negra - escrava e liberta - os quais têm alargado o horizonte dos estudos sobre escravidão e pós-abolição no Brasil, problematizando questões, até então, pouco investigadas.

A obra de Mary Karasch ${ }^{1}$ constitui-se em importante referência ao abordar as condições de vida no cativeiro, as causas específicas da mortalidade dos escravos, e as doenças que mais os acometiam - enfatizando aquelas desenvolvidas em decorrência do trabalho - bem como as ações para manter e restabelecer a saúde. Essas reflexões surgem, portanto, a partir da demografia histórica de fins dos anos 1970 e início dos 1980.

O amplo panorama revelado por Karasch abriu outras frentes de investigações na historiografia brasileira, aprofundando ou construindo novas abordagens. ${ }^{2}$ Um desses novos campos trata da construção do pensamento médico a partir da especificidade escravista brasileira, ao centrar-se nas questões da doença, tratamento e comportamento dos cativos no Brasil. ${ }^{3}$

A partir dos caminhos abertos pela demografia histórica e pela pioneira pesquisa de Karash, outros trabalhos investigaram as doenças que mais atingiam escravos e forros, africanos e descendentes, usando como fontes os registros de óbitos, entrada e saída de hospitais, inventários post mortem e anúncios de escravos fugidos. Essas análises, quantitativas e qualitativas, contribuem para o melhor conhecimento sobre as condições de saúde dos cativos. ${ }^{4}$ Nessa linha, vale destacar os trabalhos sobre aleitamento por amas

\footnotetext{
${ }^{1}$ KARASCH, Mary. A Vida dos Escravos no Rio de Janeiro (1808-1850). São Paulo, Companhia das Letras, 2000.

${ }^{2}$ Ver PORTO, Ângela. "A saúde dos escravos da historiografia brasileira”. XII Encontro Regional de História, ANPUH/RJ. Rio de Janeiro, 2006, pp.1-9.

${ }^{3}$ Sobre a temática ver: ENGEMANN, Carlos. "Vida cativa: condições materiais de vida nos grandes plantéis do sudeste brasileiro do século XIX”. In FRAGOSO, João et al (Orgs). Nas rotas do Império. Vitória, Edufes; Lisboa, IICT, 2006, p.423-445. OLIVEIRA, Rogério Siqueira de. Assistência à saúde dos escravos em Juiz de Fora (1850-1888). Rio de Janeiro, Centro Federal de Educação Tecnológica Celso Suckow da Fonseca, 2016 (Dissertação de Mestrado). BARBOSA, K. V. O. "Escravidão e saúde nas fazendas cafeeiras do Vale do Paraíba fluminense, século XIX”. Rio de Janeiro, Revista da Associação Brasileira de Pesquisadores(as) Negros(as) - ABPN, 2014, v. 6, pp. 25-49. EUGENIO, Alisson. "Reflexões médicas sobre as condições de saúde da população escrava no Brasil do século XIX". Salvador, Afro-Ásia, 2010, 42, pp. 125-156. LONER, Beatriz Ana et al. "Enfermidade e morte: os escravos na cidade de Pelotas, 1870-1880". Rio de Janeiro, História, Ciências, Saúde-Manguinhos, 2012, v. 19, suplemento 1, pp. 133-152. MARIOSA, Rosilene Maria. Tratamento e Doenças de Escravos da Fazenda Santo Antônio do Paiol - 1850-1888. Vassouras, Universidade Severino Sombra, 2006 (Dissertação de Mestrado). PEREIRA, Julio C. M. da S. "Práticas de saúde, doenças e sociabilidade escrava na Imperial Fazenda de Santa Cruz, na segunda metade do século XIX”. São Paulo, Histórica, 2009, v.35, pp. 01-16

${ }^{4}$ AMANTINO, Márcia. "As condições físicas e de saúde dos escravos fugitivos anunciados no Jornal do Commercio (RJ) em 1850”. Rio de Janeiro, História, Ciências, Saúde - Manguinhos, 2007, vol.14, no.4, pp.13771399. ENGEMANN, Carlos. "Vida cativa: condições materiais de vida nos grandes plantéis do sudeste brasileiro do século XIX”. In Fragoso, João et al. (Orgs). Nas rotas do Império. Vitória, Edufes; Lisboa, IICT, 2006.
} 
de leite ${ }^{5}$ sobre a relação entre o tráfico atlântico e o desenvolvimento de epidemias, ${ }^{6}$ sobre os cuidados dispensados aos escravos pós-tráfico atlântico, sobre a atuação de curandeiros populares ${ }^{7}$ e de parteiras escravas ou libertas, bem como sobre as práticas de cura e sobre a utilização do corpo escravo no ensino médico. ${ }^{8}$

Outros trabalhos recentes têm revelado ainda que a saúde dos cativos não era assunto de pouca monta e não obstante o número reduzido de hospitais no território brasileiro, foram montados aparatos particulares para a assistência à saúde dos escravos, ampliando os limites da historiografia consagrada sobre escravidão ao demonstrar que os fazendeiros desenvolveram, para várias regiões do país, estruturas voltadas para o cuidado e preservação da saúde dos cativos. A despeito das motivações dos escravocratas - discutidas pelos autores - eles montaram redes privadas de assistência, constituídas por enfermarias, boticas, hospitais, contratação de médicos de partido e serviço de enfermagem. ${ }^{9}$

p.423-445. BARRETO, Maria Renilda; PIMENTA, Tania Salgado. “A saúde dos escravos na Bahia oitocentista através do Hospital da Misericórdia”. Mato Grosso, Territórios e Fronteiras (Online), 2013, v. 2, pp. 75-90.

${ }^{5}$ KOUTSOUKOS, Sandra Sofia Machado. “ ‘Amas mercenárias': o discurso dos doutores em medicina e os retratos de amas - Brasil, segunda metade do século XIX”. Rio de Janeiro, História, Ciências, Saúde Manguinhos, 2009, v.16, n.2, pp.305-324. CARULA, Karoline. "Perigosas amas de leite: aleitamento materno, ciência e escravidão em A Mãe de Família". Rio de Janeiro, História, Ciências, Saúde-Manguinhos (Impresso), 2012, v. 19, pp. 197-214.

${ }^{6}$ CHALHOUB, Sidney. Cidade Febril. São Paulo, Companhia das Letras, 1999. KODAMA, Kaori. "Os debates pelo fim do tráfico no periódico 'O Philantropo' (1849-1852) e a formação do povo: doenças, raça e escravidão". São Paulo, Revista Brasileira de História, 2008, v. 28, p. 407-430. BELTRÃO, Jane Felipe. "Cólera e gente de cores ou o acesso aos Socorros Públicos no século XIX”. Rio de Janeiro, Physis. Revista de Saúde Coletiva, 2004, v. 14, n. 2, pp. 257-282. DAVID, Onildo Reis. O inimigo invisível - epidemia na Bahia no século XIX. Salvador, EDUFBA/Sarah Letras, 1996. DINIZ, Ariosvaldo da Silva. "As artes de curar nos tempos de cólera. Recife, 1856”. In CHALHOUB, Sidney; MARQUES, Vera Regina Beltrão; SAMPAIO, Gabriela dos Reis; GALVÃO Sobrinho, Carlos R. (Orgs) Artes e ofícios de curar no Brasil: capítulos de história social. Campinas, Editora da Unicamp, 2003. pp. 355-385. KODAMA, Kaori; PIMENTA, Tânia; BASTOS, Francisco Inácio; BELLIDO, Jaime. "Mortalidade escrava durante a epidemia de cólera no Rio de Janeiro (1855-1856): uma análise preliminar". Rio de Janeiro, História, Ciências, Saúde - Manguinhos, 2012, v.19, supl., pp.59-79.

${ }^{7}$ SAMPAIO, Gabriela dos Reis. Juca Rosa: um pai de santo no Rio de Janeiro Imperial. Rio de Janeiro, Arquivo Nacional, 2009; XAVIER, Regina Célia. Religiosidade e Escravidão, século XIX: mestre Tito. Porto Alegre, Editora da UFRGS, 2008.

${ }^{8}$ LIMA, Silvio C. de Souza. O corpo escravo como objeto das práticas médicas no Rio de Janeiro (1830-1850). Rio de Janeiro, Fiocruz, 2011 (Tese de Doutoramento).

${ }^{9}$ BARBOSA, Keith. Valéria de Oliveira. O. "Escravidão e saúde nas fazendas cafeeiras do Vale do Paraíba fluminense, século XIX”. Rio de Janeiro, Revista da Associação Brasileira de Pesquisadores(as) Negros(as) - ABPN, 2014, v. 6, pp. 25-49; REIS, Thiago de Souza dos Reis. Morte e escravidão: padrões de morte da população escrava de Vassouras, 1865-1888. Rio de Janeiro, Universidade Federal do Rio de Janeiro, 2011 (Dissertação de Mestrado); PEREIRA, Julio C. M. da S. "Práticas de saúde, doenças e sociabilidade escrava na Imperial Fazenda de Santa Cruz, na segunda metade do século XIX”. São Paulo, Histórica (Online), 2009, v.35, pp. 01-16; OLIVEIRA, Rogério Siqueira de. Assistência à saúde dos escravos em Juiz de Fora (1850-1888). Rio de Janeiro, Centro Federal 
Os trabalhos indicados nesta breve introdução possibilitam compreender questões inscritas no universo da saúde, da doença, das formas de cura, dos terapeutas, bem como da ciência e, finalmente, nos conduz a refletir sobre as relações sociais e o mundo do trabalho escravo. Dentre as possíveis agendas de investigação no campo da história da saúde, da escravidão e da assistência, vamos nos deter na criação da Maternidade Santa Isabel, um espaço privado para cuidar de parturientes escravas, libertas e imigrantes, na cidade do Rio de Janeiro do último quartel do século XIX. Trata-se, portanto, de uma instituição urbana de assistência destinada a um público delimitado. Qual o significado da criação dessa maternidade? Foi a maternidade uma oportunidade de negócio? Qual a relação entre maternidade e ensino médico? Estariam os corpos das escravas e libertas a serviço da ginecologia e obstetrícia, nascentes especialidades médicas? Quem foram os atores sociais envolvidos nesse projeto e quais os seus argumentos?

\section{Panorama da assistência ao parto na cidade do Rio de Janeiro da segunda metade do século XIX}

Para o período estudado a cidade do Rio de Janeiro possuía, aproximadamente, 226.033 habitantes, sendo 133.880 homens e 92.153 mulheres, segundo o Recenseamento do Brasil em 1872. Com a importância política conferida ao município neutro, a grande movimentação do porto e à existência da Faculdade de Medicina, a cidade foi palco de um significativo mercado de oferta de serviços de saúde, conforme podemos perceber nos anúncios publicados nos jornais quotidianos que serão explorados ao longo do texto.

No Brasil de fins do século XIX, nenhuma outra cidade poderia ombrear com o Rio de Janeiro em número de hospitais e casas de saúde. Havia o Hospital da Santa Casa da Misericórdia, o Hospital do Lázaros, o Hospital da Venerável Ordem Terceira de Nossa Senhora do Monte do Carmo, o Hospital da Ordem Terceira de São Francisco da Penitência, o Hospital da Ordem Terceira dos Mínimos de São Francisco de Paula, o Hospício D. Pedro II, o Hospital da Sociedade Portuguesa de Beneficência, Hospital Frei Antônio, Policlínica Geral do Rio de Janeiro, o Hospício de Nossa Senhora das Dores, Hospício Nossa Senhora do Socorro, Hospício de São João Batista da Lagoa e o Hospital de São Sebastião. ${ }^{10}$

de Educação Tecnológica Celso Suckow da Fonseca, 2016 (Dissertação de Mestrado); MARIOSA, Rosilene Maria. Tratamento e Doenças de Escravos da Fazenda Santo Antônio do Paiol - 1850-1888. Vassouras, Universidade Severino Sombra, 2006 (Dissertação de Mestrado).

${ }^{10}$ Para uma relação completa das instituições de saúde no Rio de Janeiro ver SANGLARD, Gisele; PORTO, 
Apesar de mais de uma dezena de hospitais civis, eles não eram hospitais gerais, exceto os da Santa Casa da Misericórdia que, por sua associação com a Faculdade de Medicina e com o poder público, atendiam a todos que pudessem pagar o tratamento ou que apresentassem pedidos encaminhamento das autoridades públicas. Os demais eram destinados às doenças infectocontagiosas, à loucura ou aos grupos étnicos que fundavam e mantinham instituições de assistência. E o parto? Onde acontecia? Quem atendia as grávidas e paridas?

Ao longo de todo o século XIX a assistência ao parto foi uma atividade desempenhada por parteiras práticas ou diplomadas ${ }^{11}$ seja no espaço doméstico ou nas casas de parto. 0 parto era um assunto feminino e envolvia diferentes redes de solidariedade e de exercício de poder. Maria Lúcia Mott ${ }^{12}$ estudou a trajetória dessas profissionais a partir da formação profissional, do perfil social, das atribuições, da fiscalização e regulamentação da profissão, bem como da inserção delas no mercado de trabalho.

As parteiras faziam partos, examinavam amas-de-leite, cuidavam da mãe e do recém-nascido, levavam à pia batismal as crianças que ajudaram a vir ao mundo, eram convocadas como peritas em exames médico-legais, passavam atestado de saúde e de doença, sangravam, vacinavam, faziam abortos, tratavam de doenças venéreas, ciclos menstruais irregulares, amamentação, esterilidade, estupro, contracepção e infertilidade. Elas também ofereciam crianças para adoção ou as encaminhavam às rodas dos expostos. Havia casos em que as parteiras recebiam escravas como pensionistas e após o parto as alugar como amas-de-leite. Maria Lucia Mott recuperou o relato do suíço Charles Prade ${ }^{13}$ sobre a existência de uma parteira, dona de uma villa d'accouchement

\footnotetext{
Ângela; FONSECA, Maria Rachel Fróes da; COSTA, Renato da Gama Rosa (Orgs). História da Saúde no Rio de Janeiro: instituições e patrimônio arquitetônico (1808-1958). Rio de Janeiro, Editora Fiocruz, 2008.

${ }^{11}$ As parteiras subdividiam-se em três categorias: as leigas, as examinadas e as diplomadas. As primeiras possuíam apenas o saber empírico-sensorial; as examinadas eram avaliadas por cirurgiões indicados pela Fisicatura-Mor; e as diplomadas eram aquelas que cursavam obstetrícia na Faculdade de Medicina da Bahia ou do Rio de Janeiro, a partir de 1832, ou que se fizeram o curso no exterior mas validaram o diploma nas faculdades brasileiras.

${ }^{12}$ MOTT, Maria Lúcia. Parto, parteiras e parturientes no século XIX. Mme Durocher e sua época. São Paulo, USP, (Tese de Doutoramento), 1998; MOTT, Maria Lúcia. “A parteira ignorante: um erro de diagnóstico médico?”. Santa Catarina, Estudos Feministas, ano 7, pp. 25-36, 1999; MOTT, Maria Lúcia. "As parteiras e a assistência ao parto em São Paulo nas primeiras décadas do século XX". São Paulo, Revista do Instituto Histórico Geográfico de São Paulo, 2002, pp. 67-84; MOTT, Maria Lúcia. "Assistência ao parto: do domicílio ao hospital". São Paulo: História, 2002, pp. 197-219; MOTT, Maria Lúcia . "Madame Durocher, modista e parteira". Santa Catarina, Estudos Feministas, 1994, n.1, vol.2, pp; 101-116; MOTT, Maria Lúcia. "O curso de partos: deve ou não haver parteiras?” São Paulo, Cadernos de Pesquisa, 1999, pp.133-160; MOTT, Maria Lúcia. Parteiras: o outro lado da profissão. Niterói: Gênero, 2005, Vol. 6, no 1, p.117-140.
}

${ }^{13}$ PRADEZ, Charles. Nouvelles études sur le Brésil. Paris, Ernest Thorin, 1872. 
(casa de parto) que recebia escravas grávidas e as alugava após o parto, na condição de ama-de-leite. Outra francesa - Clementine Sonjean - anunciou no Jornal do Comércio (Rio de Janeiro) a prestação dos mesmos serviços. ${ }^{14}$

Esse protagonismo feminino sobre o parto, no Brasil, passaria por mudanças a partir da criação da Escola de Cirurgia, em 1808, com a chegada da Corte Portuguesa. Doravante, outro personagem fará parte da cena do parto, muito timidamente na primeira metade do século XIX, ganhando força a partir das últimas décadas, com o desenvolvimento da ginecologia e da obstetrícia. Trata-se dos médicos, profissionais que vão se inserir no mercado de trabalho, disputando espaço profissional com as parteiras. Em outros artigos discuti a trajetória do ingresso masculino na cena do parto, movimento que se iniciou na Europa no século XVII e no Brasil, no século XIX. ${ }^{15}$

Médicos e parteiras disputaram a assistência ao parto, tanto na casa da parturiente, como nas casas de partos, ou nas casas de saúde que possuíam enfermarias para tal fim. Em verdade, os anúncios das casas de saúde vendiam todos os tipos de serviço: operações, sangrias, ventosas, socorros espirituais, enfermarias para doenças contagiosas, enfermarias para crianças e "enfermaria de maternidade". Os doentes pagavam adiantado e todas ofereciam enfermarias para escravos/as. Esses espaços destinados aos cativos eram os de piores condições, em local menos privilegiado dos prédios. Havia uma hegemonia de preços nos estabelecimentos que postavam anúncios nos jornais. Em relação aos escravos o custo da enfermaria variava entre $1 \$ 000$ e $1 \$ 600$ por dia. ${ }^{16}$

Vale ressaltar a existência de espaços de assistência à saúde destinados, exclusivamente, a escravos, como a Casa de Saúde da Companhia Previdência, ${ }^{17}$ que tratava de cativos assegurados e não assegurados, bem como de negros libertos. A instituição localizava-se na Rua Mattacavallos, número 88 e o custo do tratamento anunciado era o mesmo do Hospital da Misericórdia. 0 empreendimento foi organizado pelos médicos Antônio Martins Pinheiro (diretor),

\footnotetext{
${ }^{14}$ MOTT, Maria Lúcia. Parteiras: o outro lado da profissão. Niterói: Gênero. Vol. 6, no 1, p.117-140, 2005.

${ }^{15}$ BARRETO, Maria Renilda. "Assistência ao nascimento na Bahia oitocentista". Rio de Janeiro, História, Ciências, Saúde-Manguinhos, 2008, v. 15, p. 901-925; BARRETO, Maria Renilda. "A Ciência do Parto nos Manuais Portugueses de Obstetrícia”. Niterói, Gênero, 2007, v. 7, pp. 217-234.

${ }^{16}$ Almanack Laemmert 1862; 1863; Jornal do Commercio, 1862.

${ }^{17}$ Companhia que se dedicava, exclusivamente aos seguros de vida para escravos, fundada como sociedade anônima em 1854. Entre seus acionistas estavam o Barão de Mauá, o Conselheiro Ângelo Moniz da Silva Ferraz e o Comendador Manoel Maria Bregaro. Sobre esse tema vide PAYAR, A.J.F. A Escravidão entre os Seguros: as seguradoras de escravos na Província do Rio de Janeiro (1831-1888). São Paulo, USP, 2012, (Dissertação de Mestrado); NOGUERÓL, L.P. F. "Seguro de Vida para Escravos no Rio de Janeiro no Século XIX: mais um negócio”. In VII Encontro Escravidão e Liberdade no Brasil Meridional. Curitiba 2015.
} 
José Pereira Rego (médico) e Antônio Ferreira França (operador). ${ }^{18}$ Por fim, cabe registrar outro espaço destinado aos cativos, como a Casa de Saúde do Dr. Azevedo, localizada na Rua das Laranjeiras, número 47-B, tendo funcionado entre $1868-1871^{19}$, cuja clientela atendida era majoritariamente do Catete e de Laranjeiras.

Em relação ao atendimento de parturientes destacamos a Casa de Saúde Nossa Senhora da Ajuda, fundada em 1863 pelo médico Manuel Joaquim Fernandes Eiras, localizada na Rua da Ajuda, ${ }^{\text {os }} 66$ e 68. Essa era uma das ruas mais movimentadas da cidade e, além da casa de saúde, foi instalada uma maternidade, conforme registro dos anúncios. ${ }^{20}$ No ano de fundação dessa instituição a parteira Madame Durocher, um dos principais nomes da cidade, que ali atendia, informava a sua clientela e aos interessados que a maternidade ou enfermaria de parto, contígua à Casa de Saúde, possuía "sala própria para escravas, fornecendo tudo o que for mister, inclusive roupas" ${ }^{21}$. A parteira francesa, que dividia o atendimento com outra estrangeira - Tygna - publicou um longo anúncio sobre o novo estabelecimento, que contava com nomes proeminentes no campo da parturição: o do médico Feijó e o dela.

As pessoas que mandarem suas escravas para esta enfermaria podem certificarse do tratamento, desvelos e atenções que se prodigalizam a todos os doentes (...) quer por parte dos médicos, quer por parte das parteiras, todos os doentes têm direitos às mesmas atenções, remédios, etc, pois a caridade não conhece posições, nem é distintiva para o livre ou escravo. ${ }^{22}$

As mulheres de poucos recursos, tais como costureiras, floristas, modistas e artistas nacionais ou estrangeiras, que não desejavam recorrer aos serviços da Santa Casa da Misericórdia, poderiam fazer uso da "sala para mulheres livres". O custo dos serviços obstétricos envolvia o pagamento das diárias mais o valor do parto, sendo para as livres $3 \$ 000$ mais $20 \$ 000$ e para as escravas $1 \$ 600$ mais $10 \$ 000 .{ }^{23}$ Além das parteiras mencionadas acima, compunham o corpo clínico do estabelecimento alguns médicos ligados à Sociedade de Medicina do Rio de Janeiro, à Faculdade de Medicina e à Junta de Higiene Pública, como João Vicente de Torres Homem, Francisco de Paula Costa, Matheus

\footnotetext{
$\overline{{ }^{18} \text { Correio da Tarde, } 1858 .}$

${ }^{19}$ Almanack Laemmert 1868, 1869, 1870.

${ }^{20}$ Almanack Laemmert, 1863; Diário do Rio de Janeiro, 01/01/1864.

${ }^{21}$ Diário do Rio de Janeiro, 19 de maio de 1863, p. 3.

${ }^{22}$ Diário do Rio de Janeiro, 19 de maio de 1863, p. 3.

${ }^{23}$ Correio Mercantil, 14/10/1862; Jornal do Commercio, 15/03/1863, p.4.
} 
Alves de Andrade e Luís da Cunha Feijó.

Foi nesse cenário que, em 1877, o médico José Rodrigues dos Santos, professor da Faculdade de Medicina do Rio de Janeiro, instalou no bairro de Santa Isabel, no Boulevard Vinte e Oito de Setembro, $n^{\circ} 12$, sua clínica privada, a qual deu o nome de Casa de Saúde e Maternidade Santa Isabel. A instituição contava com 30 leitos e atendia a população do bairro. ${ }^{24}$ Veremos, a seguir, como essa instituição vai passar do âmbito privado para o público, articulando atores sociais, projetos políticos e científicos, bem como oportunidades de negócio.

Fonte: Revista das Notabilidades Profissionais, Comerciais e Industriais do Rio de Janeiro, Suplemento do Almanack Laemmert, 1863, p. 7.

CASAS DE SAJDE.

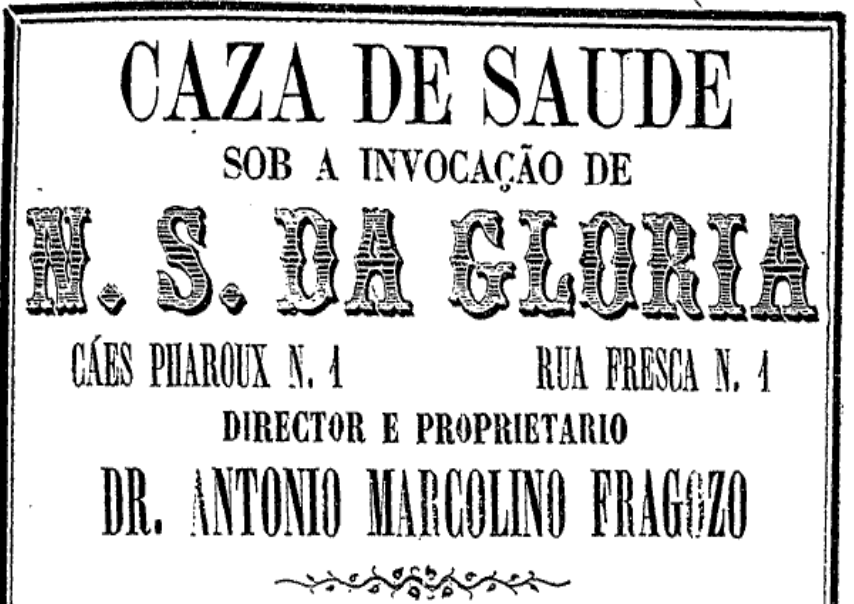

A Cusa de Saude do Dr. A. H. Fragoso, situada en uma posiŗào aprazivel, pittoresca $\mathrm{c}$ sandavel, tem a immensa yantagem de, com todas as condiçöes hygienicas desejarcis, achar-se mui perto do centro da cidade, facilitando assim o transporte dos doentes o o poderem ser estes risilados diariancnte. Os Maritimos seguramente não encontraráó outra Cata de Saude mais commoda, pois uma das cntradas do estabelecimento acha-se mesmo em frente ao desembarque nuais geralmente escolhido (Cirs Praroux.)

0 edificio, achando-sc situado em uma rasta praşa, livre por tres faces e todo guar necido de jancllas, sâo os seus quartos c salōes perfeitamente ventilados c claros; todos elles são mui csparcosos c completamente independentes uns dos outros. Nenhum doente, nem mesmo os escravos, scrii collocado no pavimento terreo.

A Caza recebe doentes de ambos os sexos livres e escravos. As enfermarias e quarlos dos homens são separados dos das mulheres. Ha salōes e quarlos especiaes para os doentes affectados de molestias da pelle; syphiliticus, dos olhos e das vias urinarias. Ha uma Maternidade onde as parlurientes enconiraráõ todas as commodidades e cuidados necessarios. Ha uma enfermaria para criances, as quaes serão tratadas com todo 0 carinho. Existem na Caza banbos de agua doce, quentes e frios, de agua do mar, de cachoeira, de chuva e duchas. Um Medico residente no estabelecimento prestará immediato auxilio ao doente, logo que este entrar. Os doentes são recebidos a qualqu ser hora do dia ou da noile e podem ser visitados todos os dias. 0s doentes de fóra da cidade terảo conducção, pedindo-a. Não se recebem bexiguentos. Os soccorros espirituaes serão prestados de prompto aos doentes, pelo Capellão da Caza. Harerá missa aosdomingos e dias santos.

TAIELCA.

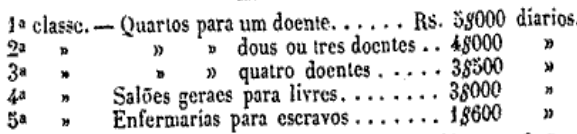

Os doentes pagaráij 15 dias adiantados, ou prestando fiança idonea o farão apenas terminada 2 quinzena. Restitue-se a differença, caso não se completem os 15 dias. Os moribundos pagão o duplo dos 'presos acima marcados e a quinzena, sem direito á restituiç̧ăo da differença.

MATERNIDADE.

1 classe-Doentes livres. 0s $\mathrm{I}$ dias incluido o parto 608000

Qa

24 ARAÚJO, Achiles Ribeiro de. A assistência médica hospitalar no Rio de Janeiro no século XIX. Rio de Janeiro, MEC, 1982, pp. 197-198. 


\section{A Maternidade Santa Isabel: "Um estabelecimento pio em favor da pobreza"?}

A criação de maternidades não pode ser compreendida como um fato isolado, resultado exclusivo do esforço da comunidade médica, à margem do campo da saúde pública, ou desarticulada do amplo espectro das relações sociais, políticas, econômicas e culturais, tampouco exclusivamente como uma vitória do saber médico na disputa pelo poder sobre o corpo feminino. O nosso desafio é discutir a criação da Maternidade Santa Isabel, na cidade do Rio de Janeiro, a partir de múltiplas perspectivas. Defendemos que essa maternidade foi um projeto que agregou interesses econômicos, científicos, pedagógicos e de assistência à saúde.

No fim do século XIX a cidade do Rio de Janeiro se transformava rapidamente. A efervescência pode ser explicada pelos movimentos abolicionista e republicano, pelo aumento demográfico proporcionado pela chegada de imigrantes, bem como pela migração de libertos, pela atuação intelectual de grupos oriundos das Escolas de Engenharia, de Direito, de Medicina e do Colégio Pedro II. Acrescente-se os intelectuais pertencentes a Academia Imperial de Medicina, a Sociedade de Medicina do Rio de Janeiro, o Instituto Histórico e Geográfico Brasileiro e o Museu Nacional. ${ }^{25}$

A escravidão, a saúde e a doença foram temas que sacudiram os ânimos e dividiram opiniões. Em pauta, estava a necessidade de fundação de uma maternidade, tratada publicamente nas Conferências Populares da Glória, nos artigos circulantes na imprensa leiga, nas sessões da Academia de Medicina, da Câmara Municipal e da Faculdade de Medicina. Para alguns médicos as diversas casas de partos não eram suficientes para atender às necessidades das mulheres grávidas, principalmente daquelas que não podiam pagar por serviços particulares. Outro argumento foi o deslocamento das aulas práticas de partos e de doenças de mulheres - que ocorriam nas enfermarias do Hospital da Santa Casa - para uma instituição voltada, exclusivamente, ao atendimento obstétrico e ginecológico. Foi com esse discurso que os médicos tentavam convencer as autoridades públicas a financiarem a primeira maternidade da cidade, mantida pela municipalidade.

\footnotetext{
${ }^{25}$ Outras instituições poderiam ser citadas, contudo optamos por aquelas que se ocuparam dos temas que tangenciam esse artigo: saúde, doença, hospitais e escravidão.
} 


\subsection{Atores envolvidos}

Dentre os vários atores sociais envolvidos com a criação de maternidades daremos destaque para José Rodrigues dos Santos. ${ }^{26}$ Ele fez parte do grupo de médicos, ligado ao ensino, que abriu, dirigiu e clinicou em casas de saúde. Santos nasceu no Rio de Janeiro, em 10 de abril de 1852, e faleceu em 1905. Estudou medicina nessa mesma cidade, diplomou-se em 1873, especializou-se em obstetrícia e ginecologia, foi assistente da clínica de partos da Faculdade de Medicina. Após a conclusão do curso foi para a Europa, esteve na Maternidade de Port Royal, manteve contato com Adolpho Pinard, escreveu obras sobre obstetrícia, destacando-se Clinique Obstetricale, prefaciada por Pinard. Foi membro de destacadas academias científicas internacionais, dentre elas a Sociedade de Higiene e a Sociedade Química de Paris, as Sociedades de Obstetrícia de Paris e da Filadélfia. No Brasil foi membro da Academia Imperial de Medicina, da Sociedade Médico-Cirúrgica e do Instituto Farmacêutico. Também angariou títulos e honras: foi Cavaleiro da Ordem de Nossa Senhora da Conceição de Villa Viçosa, em Portugal. ${ }^{27}$

Em 4 de janeiro de 1877 José Rodrigues dos Santos enviou solicitação à Câmara Municipal do Rio em prol da criação de uma maternidade.. Ele apelou à compaixão dos vereadores para com as mulheres necessitadas, definidas pelo requerente como aquelas que "não encontram um leito que suporte suas dores, nem um pano que cubra a nudez de seus filhos" 28 ; mostrou o descompasso entre o Brasil e a "velha Europa", onde localidades como Paris e Reino da Áustria possuíam "abrigos" para mulheres pobres, custeados pela municipalidade; afirmou que a população da cidade não tinha um crescimento proporcional ao nascimento de crianças e creditava tal déficit à falta de maternidades; defendeu a existência de um núcleo de amas para o serviço particular, com documento (guia) de garantia de boa saúde e qualidade do leite; e por fim, acrescentou que a criação das maternidades refletia uma sociedade que valorizava a mulher enquanto reprodutora da espécie:

(...) e não são, senhores, mero luxo estes edifícios, é uma necessidade vigorosa, um auxílio indispensável, que devemos prestar as mulheres, criando essas

\footnotetext{
${ }^{26}$ Sobre médicos, políticos, intelecuais e funcionários públicos no Rio de Janeiro que defenderam a proteção da mulher e da criança ver FERREIRA, Luiz Otávio; SANGLARD, Gisele; PIMENTA, Tânia Salgado; BARRETO, Maria Renilda Nery; FREIRE, Maria Martha de Luna (Orgs). Filantropos da Nação: sociedade, saúde e assistência no Brasil e em Portugal. Rio de Janeiro, FGV/FAPERJ, 2015, p. 185-202.

${ }^{27}$ BLAKE, Augusto Victorino Alves Sacramento. Diccionario Bibliographico Brasileiro. Rio de Janeiro, Conselho Federal de Cultura, 1970.

${ }^{28}$ Arquivo Municipal da Cidade do Rio de Janeiro, Códice 46-2-32.
} 
casas, em que elas possam preencher uma função - a reprodução da espécie - rodeadas daqueles cuidados e abrigos indispensáveis, que, entre nós, só é privilégio das mais abastadas. ${ }^{29}$

A campanha foi vitoriosa e o projeto foi aprovado pelo Conselheiro Sodré Pereira, então Ministro do Império. Santos foi nomeado diretor da Maternidade e incumbido, através de portaria datada de 16 de março de 1880, a escolher o edifício onde deveria ser estabelecida a Maternidade Municipal de Santa Isabel. Enquanto a maternidade não possuía prédio próprio, passou a funcionar em uma enfermaria da Casa de Saúde Nossa Senhora da Ajuda, de acordo com um contrato firmado entre a Direção da Faculdade de Medicina, os diretores da Casa de Saúde Nossa Senhora da Ajuda e a Câmara Municipal. ${ }^{30}$ Pelo aluguel da referida enfermaria, os cofres públicos pagavam anualmente 10:000\$000 (dez contos de réis).

José Rodrigues dos Santos empreendeu esforços junto à comunidade religiosa e aos representantes legislativos para angariar recursos destinados à construção de um prédio para a Maternidade Santa Isabel. O terreno, localizado na praia da Lapa e adjacente ao Convento do Carmo, foi cedido pela Ordem Carmelitana Fluminense. Em maio de 1889 o Tesouro Nacional disponibilizou 30:000 \$000 (trinta contos de réis) para iniciar as obras. ${ }^{31}$

Santos ocupava um lugar bem demarcado no seio da aristocracia carioca. Ele contou com o apoio do Barão de Lavradio, então presidente da Junta Central de Higiene Pública, membros da Câmara Municipal, do clero, bem como do Imperador D. Pedro II. A municipalidade patenteou um projeto que nasceu da iniciativa particular de José Rodrigues dos Santos, em 1877, e que foi incorporada pelo poder público em 1880.

\subsection{O perfil das parturientes}

A maternidade possuía caráter público, admitindo todas as mulheres, sem distinção de cor, estatuto jurídico, civil ou religioso, desde que grávidas e no oitavo mês de gestação, exceto as que estivessem em eminência de aborto ou parto prematuro. As grávidas eram examinadas em dois dias da semana para determinar o tempo de gravidez e, uma vez admitidas, ocupavam um leito até que iniciasse o trabalho de parto, em seguida, eram transportadas para

\footnotetext{
${ }^{29}$ Arquivo Municipal da Cidade do Rio de Janeiro, Códice 46-2-32, pp.3-4.

${ }^{30}$ Enquanto a Corte esteve fixada na Província do Rio de Janeiro, a administração do município neutro esteve sujeita ao Governo Central através do Ministério do Império.

${ }^{31}$ Arquivo Nacional, IS3 29.
} 
uma sala especial até o nascimento da criança. 0 atendimento custava $20 \$ 000$ a diária e as mulheres sem recursos deveriam trazer um atestado de pobreza, assinado pelo inspetor do quarteirão. As escravas, aptas ao aluguel como amas de leite, seriam examinadas, ganhariam uma guia de aptidão e deveriam se submeter aos regulamentos da maternidade. Como podemos perceber esse serviço não ficou restrito às parteiras, fazendo parte do universo profissional dos médicos. Finalmente, previa o regulamento que as crianças abandonadas seriam recolhidas na Casa dos Expostos. Diante dessa informação surge uma indagação: será que as mulheres escravas, escolhidas como amas de leite, eram separadas dos seus filhos e esses encaminhados à Roda dos Enjeitados?

Em 1882 Santos enviou à Câmara Municipal o relatório do movimento de partos ocorrido na Maternidade Santa Isabel, entre abril e dezembro de 1881, quando 48 mulheres deram à luz e outras 13 estavam internadas, aguardando o nascimento dos bebês. Das que passaram pelo trabalho de parto (48) quase todas eram brasileiras, com exceção de 3 - uma italiana e duas portuguesas - e possuíam a idade média de 25 anos. As parturientes foram, em sua maioria, mulheres de cor, sendo 39 pardas, 1 negra e 8 brancas. Das atendidas, 29 eram escravas, 18 livres e 1 não identificada; apenas duas eram casadas e 46 solteiras; 12 eram primíparas, 35 eram multíparas e 1 não identificada; dos 47 partos realizados, 7 sofreram intervenções, seja com uso de fórceps ou de manobras obstétricas - os demais foram considerados naturais; das 47 gestantes que deram à luz no hospital, duas faleceram. ${ }^{32}$ Foram elas Francisca Ferreira, de 28 anos, branca, livre, casada, mãe de outros filhos, que veio a falecer de infecção generalizada e, segundo o diretor, ingressara na maternidade com ruptura do útero, em situação de difícil reversibilidade; a outra gestante foi Cantalina, 20 anos, brasileira, parda, escrava, solteira, $1^{\underline{a}}$ gravidez, deu à luz prematuramente e foi a óbito. Para Rodrigues dos Santos a morte dessa mulher foi causada por uma anemia profunda e não pelo parto. ${ }^{33}$

Entre janeiro e setembro de 1882 a Maternidade atendeu 103 mulheres, 35 livres e 68 escravas. Infelizmente o diretor foi econômico nas informações limitando-se ao nome das pacientes e ao número de atendimentos. Ele considerava que o número de atendidas era considerável e só não era maior porque o curso de obstetrícia afugentava as parturientes. É provável que essas mulheres não desejassem transformar os seus corpos em instrumento pedagógico para os alunos do ensino médico.

\footnotetext{
${ }^{32}$ Uma mulher foi rejeitada por estar no início da gravidez.

${ }^{33}$ Arquivo Municipal da Cidade do Rio de Janeiro, Códice 46-2-32.
} 
Apesar da regulamentação de funcionamento da maternidade ser exclusiva para o parto, percebe-se que outros procedimentos foram realizados. $\mathrm{O}$ dr. Rodrigues dos Santos informou que atendeu uma mulher com quisto de ovário, procedendo a uma ovariotomia; uma outra com prolapso de útero; e uma terceira com pólipo uterino, o qual foi extirpado, saindo a doente curada. Estas mulheres que apresentavam doenças de senhoras, somadas às gestantes, acabaram por fornecer a Rodrigues dos Santos a possibilidade de testar medicamentos e terapêuticas, como ele próprio declarou: "experiências cheias de resultados de valor para a ciência, e que constituem o assunto de um trabalho em público". ${ }^{34}$

Assim, a construção e a sedimentação do saber médico brasileiro valeram-se dos corpos de escravos, com médicos atentos às manifestações das doenças dos cativos presentes nas ruas, residências, enfermarias. Em uma sociedade escravista não poderiam estar os médicos alheios à manifestação da doença nessa população. Os resultados desses estudos eram publicados em jornais especializados, livros e manuais didáticos. ${ }^{35}$

\subsection{Um projeto inacabado}

Às vésperas da proclamação da República, o cônego da Ordem Carmelita Fluminense, Eduardo Duarte Silva, enviou para o Conselheiro Antônio Ferreira Vianna $^{36}$, ministro do Império, uma correspondência em que afirmava ter a Ordem religiosa cedido o terreno adjacente ao quintal do Convento do Carmo para construção de uma maternidade. ${ }^{37}$

Em 1883 a Câmara Municipal resolveu fechar a Maternidade Santa Isabel, que funcionava na Casa de Saúde Nossa Senhora da Ajuda. Mas, isso não significou o fim do projeto. Seis anos depois (1889) iniciaram-se as obras da maternidade na praia da Lapa. O responsável pela planta e construção foi o engenheiro Antonio de Paula Freitas, a partir das diretrizes recomendadas

\footnotetext{
${ }^{34}$ Arquivo Municipal da Cidade do Rio de Janeiro, Códice 46-2-32.

${ }^{35}$ Sobre a publicação dos casos clínicos, observados nos corpos dos cativos ver LIMA, Silvio C. de Souza. 0 corpo escravo como objeto das práticas médicas no Rio de Janeiro (1830-1850). Rio de Janeiro, Fiocruz, 2011 (Tese de Doutoramento). Sobre as doenças de mulheres e a atuação dos médicos da Faculdade de Medicina ver PEARD, Julyan G. Race, place, and medicine. The idea of the Tropics in Nineteenth-Century brazilian medicine. Durh and London, Duke University Press, 1999.

${ }^{36}$ Antonio Ferreira Vianna foi político, jornalista, jurista, promotor público na Corte (1857), deputado em cinco legislaturas (1869-77; 1881-4; 1886-9); Ministro da Justiça (1888) e do Império (1889). (IHGB, informações disponíveis pelo site http://www.ihgb.org.br/acervo311.php?f=ACP000013)

${ }^{37}$ Convento do Carmo da Corte, 30 de abril de 1889, Arquivo Geral da Cidade do Rio de Janeiro, Códice $-46-2-32$.
} 
pela Faculdade de Medicina, especificamente do professor de ginecologia e obstetrícia Érico Marinho da Gama Coelho. Em 5 de junho de 1889 a planta da Maternidade Santa Isabel já havia sido aprovada, e o seu desenho atendia aos preceitos higiênicos defendidos pelo corpo docente da Faculdade de Medicina..$^{38}$

Em $1^{\circ}$ de maio de 1889, um documento expedido pelo Ministério dos Negócios do Império disponibilizou a quantia de 30:000\$000 (trinta contos) para dar início à construção do edifício da Maternidade da Lapa, como passou a ser denominada a Maternidade Santa Isabel, em função do novo local de instalação, no cais da Lapa.

Antonio de Paula Freitas projetou um espaço privilegiado para as aulas da cátedra de obstetrícia da Faculdade de Medicina. Sua planta seguiu o modelo pavilhonar vigente na Europa em fins do século XIX. Surgido em França, graças aos estudos do engenheiro militar Casemir Tollet, o sistema pavilhonar ou Tollet, como ficou conhecido, logo ganhou toda Europa tornando-se referência, sobretudo, na Alemanha. É caracterizado por edifícios de no máximo dois andares, que ocupavam uma grande área e neles imperava o princípio do isolamento da doença e do doente, no interior do pavilhão.

Paula Freitas aproveitou ao máximo as vantagens do terreno - de esquina - para criar dois blocos bem isolados um do outro. As questões de aeração e de exposição ao sol foram resolvidas com a presença de janelas que davam para a rua e por uma varanda voltada para o pátio interno que garantia circulação de ar constante nas dependências da maternidade. A entrada localizava-se na esquina do terreno e, através de um vestíbulo, acessava-se as alas direita e esquerda, além do anfiteatro. Na ala esquerda térrea situava-se a portaria, a secretaria, a sala de aprendiz, ao lado da sala da $2^{\mathrm{a}}$ parteira, uma enfermaria; uma escada que dava acesso ao $1^{\circ}$ andar; três salas para grávidas, um refeitório que dava acesso a dois pequenos quartos e a casa de banho; na extremidade da varanda que acompanhava esta ala estavam as latrinas.

${ }^{38}$ Arquivo Nacional, IS3 29. 
Figura 1 - Planta da Maternidade Santa Isabel

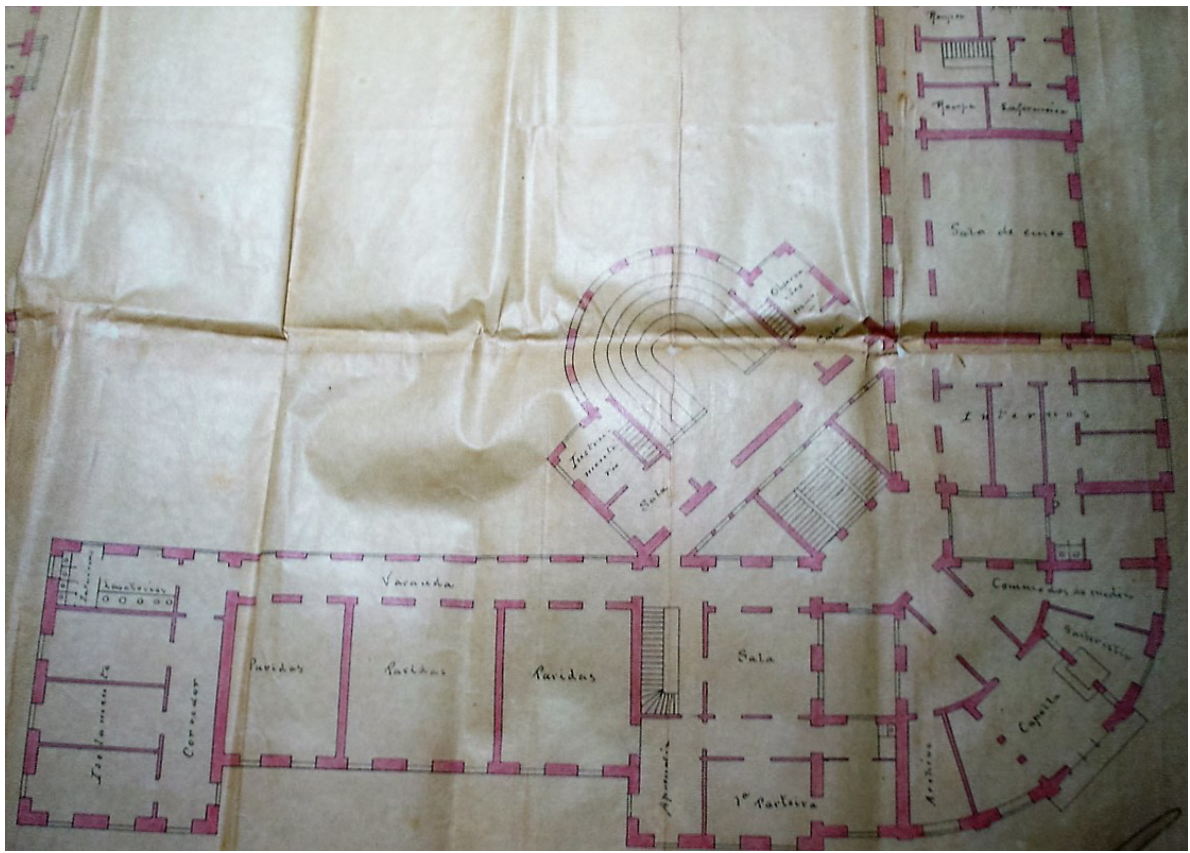

Fonte: Arquivo Nacional, Planta do segundo pavimento da Maternidade Santa Isabel, também denominada Maternidade da Lapa, assinada pelo engenheiro Antônio de Paula Freitas, em 05/06/1889.

Já na ala direita do vestíbulo, estava uma sala de espera, um vestiário e a sala de consultas. Nesse mesmo corredor ficavam duas salas para professores, uma biblioteca e um laboratório, separados por um pequeno corredor da sala de manequins, do depósito, de uma saleta e das escadas que davam acesso ao piso superior, da rouparia e de três salas de ginecologia. Ao fim do corredor estavam uma pequena sala para despejo, a casa de banho e a latrina.

Adentrando o prédio pelo vestíbulo e seguindo em frente estaria o anfiteatro para as aulas demonstrativas. Este estava na altura do $2^{\circ}$ pavimento da maternidade, era ladeado por duas salas: à esquerda o instrumentário e à direita, a sala da doente. A varanda do anfiteatro ligava-se à do $1^{\circ}$ andar, estabelecendo a comunicação entre os dois blocos.

No primeiro andar, sobre o vestíbulo, ficaria a capela e a sacristia. Em frente a ela, o acesso ao anfiteatro. $\mathrm{Na}$ ala esquerda, ficariam o arquivo, a sala da primeira parteira e da aprendiz, seguidas de três salas para paridas, um corredor e o isolamento. No fim da varanda, os lavatórios. 
$\mathrm{Na}$ ala direita do $1^{\circ}$ andar, após a sacristia estavam a sala dos internos, a sala de curso, duas enfermarias separadas por uma escada, cada qual antecedida por uma sala de roupa; duas salas de ginecologia separadas do isolamento por um corredor. Como nas demais alas, ao fim do corredor uma sala de despejo, o lavatório a latrina.

No fundo do terreno, e totalmente isolados dos outros blocos, estavam a capela mortuária e a sala de autopsia. Mais adiante o desinfectório, o quarto dos empregados, a cozinha, a copa e a dispensa - interligados à ala direita térrea do prédio principal por um corredor. ${ }^{39}$

Em 02 de maio de 1889, no apagar das luzes do Império, foram lançada a pedra inaugural do edifício e iniciadas as obras de construção da Maternidade Municipal Santa Isabel. O governo republicano manteve a intenção inicial de levar adiante o projeto da maternidade. Em 10 de setembro de 1896 foi promulgada a lei 429 que autorizava o Poder Executivo a entrar em acordo com a administração do Distrito Federal, a fim de concluir e inaugurar a maternidade.

Em setembro de 1897 o Distrito Federal retomou o orçamento para dar continuidade à construção, nesse período sob responsabilidade de Tobias Amaral. Seriam necessários 256:723\$192 (duzentos e cinquenta e seis contos, setecentos e vinte e três mil, cento e noventa e dois réis) para concluir as obras. A municipalidade recusou-se a gastar tal soma com o projeto, alegando que se encontrava em grave crise financeira e que não interessava ao Município manter a maternidade. Achava mais conveniente que a mesma ficasse a cargo da União, já que esta mantinha a Faculdade de Medicina, grande interessada no empreendimento. Outra opção seria vender a obra inacabada para a Santa Casa da Misericórdia, que concluiria o projeto e se tornaria proprietária da maternidade.

A Maternidade Santa Isabel, que cumpriu papel social demarcado pela experiência da assistência às mulheres pobres e escravas, e pelas demandas da ciência médica, não foi um projeto longevo, sendo encerrado junto com a escravidão e com a ordem política imperial. Além das divergências de interesses entre o Poder Executivo central e o Distrito Federal, e da crise econômica que atravessava o país no final do século XIX, temos que considerar as disputas políticas e acadêmicas entre os médicos que defendiam a existência das maternidades. Nesse período coexistiam os paradigmas miasmático/ambientalista e a teoria dos germes, e havia significativa controvérsia a respeito

${ }^{39}$ Agradeço a Renato Gama-Rosa Costa a descrição do edifício a partir do estudo da planta. 
da construção de hospitais em áreas de significativo povoamento e circulação de pessoas, representando um processo de negociação envolvendo vários atores, principalmente os médicos.

A partir de 1889, com a implantação da República, outros personagens destacam-se, a exemplo dos obstetras e ginecologistas Francisco Furquim Werneck de Almeida, Antonio Rodrigues Lima e Érico Marinho da Gama Coelho. Esse último foi um republicano, anticlerical e antimonarquista que proferiu e publicou inúmeros discursos polêmicos, dentre eles, a defesa do divórcio, as críticas ao "apostolado positivista" e a necessidade de assistência e proteção à mulher grávida. Sua carreira política começou em 1890, quando elegeu-se pela primeira vez Deputado Federal. Exerceu vários mandatos e durante um deles, o Congresso Nacional votou a autorização de fundos para a compra do imóvel da Rua das Laranjeiras, nํㅜ 66, onde seria instalada a Maternidade de Laranjeiras, propagandeada como a primeira instituição pública, voltada exclusivamente para o parto. Dessa forma, a República irá, gradativamente, apagar a memória da Maternidade Santa Isabel, associada à "velha medicina", ao passado escravista e monárquico.

\section{Considerações finais}

Em alguns contextos históricos e abordagens historiográficas a assistência à saúde é compreendida como uma maneira pela qual grupos sociais mais abastados garantem, além da produtividade da mão de obra, certa paz social, e provêm proteção a grupos de indivíduos alijados de qualquer rede de solidariedade.

Casas de saúde, enfermarias de partos e maternidades com espaços reservados para escravas faziam parte da estrutura de assistência à saúde na capital do Brasil ao longo do século XIX. Essas edificações foram oportunidades de negócios e de construção de especialidades médicas, a exemplo da obstetrícia e da ginecologia. Ao atender grupos excluídos da rede de solidariedade horizontal, portanto mais vulneráveis, colocavam esses doentes à mercê dos estudos acadêmicos, os quais eram publicados em periódicos leigos e especializados.

A instituição analisada nesse artigo foi significativa por revelar um projeto que associou a assistência à saúde da população cativa a um lucrativo negócio hospitalar, ao aluguel de amas de leite e à constituição da ginecologia e da obstetrícia como especialidades médicas. O empreendimento, que imbricou interesses públicos e privados, fez largo uso do apelo caritativo e piedoso em favor dos pobres. Apesar de registrar a caridade em suas estratégias retóricas, 
é importante ressaltar que as ações privadas, filantrópicas e públicas no campo da saúde e da assistência não podem ser estudadas sem a percepção de que elas envolvem práticas, saberes, instituições, representações, interesses individuais e de grupos. No Brasil, esses arranjos foram atravessados pela experiência da escravidão e matizaram alternativas de cuidados aos cativos na lógica do sistema escravista brasileiro.

A Maternidade de Santa Isabel articulou em torno do seu projeto médicos, religiosos, políticos e até o imperador D. Pedro II. Da Faculdade de Medicina e da Academia Imperial de Medicina vinham a sustentação científica; do clero, o reforço ao sentimento de caridade; das autoridades políticas, o desejo de modernizar o Brasil à luz da Europa "civilizada"; dos médicos, a necessidade de construir um campo profissional, legitimados pela expertise.

Artigo recebido para publicação em 02/11/2016

Artigo aprovado para publicação em 21/11/2016 